\title{
Belly-soaking: a behavioural solution to reduce excess body heat in the Kentish plover Charadrius alexandrinus
}

\author{
Juan A. Amat $\mathbb{\text { José }}$ A. Masero
}

\begin{abstract}
During nesting, many temperate and tropical shorebirds are exposed to direct solar radiation and face heat stress. The aim of our study was to determine whether belly-soaking (wetting of ventral plumage) contributes to reducing excess body heat in Kentish plovers Charadrius alexandrinus. We captured incubating plovers on sunny days at their exposed nests, and placed them inside cloth bags at ground level in exposed sites for 5 min. This produced an increase in the ambient temperature experienced by the plovers, as well as an increase in the body temperature of the plovers. We simulated belly-soaking by submerging the ventral parts in water for about $10 \mathrm{~s}$ immediately after removing the birds from the bag. The body temperature of the plovers was lowered after simulated belly-soaking. Our results indicate that belly-soaking is a behavioural strategy to quickly reduce body temperature in heat-stressed plovers.
\end{abstract}

Keywords Behavioural thermoregulation . Body temperature - Cooling behaviour - Heat loss . Plumage wetting $\cdot$ Shorebirds $\cdot$ Thermal stress

\footnotetext{
J. A. Amat (\&)

Department of Wetland Ecology,

Estación Biológica de Doñana, Consejo Superior de Investigaciones Científicas,

Apartado 1056, 41080 Sevilla, Spain

e-mail: amat@ebd.csic.es

J. A. Masero

Grupo de Investigación en Biología de la Conservación, Área de Zoología, Universidad de Extremadura, Avda de Elvas s/n, 06071 Badajoz, Spain
}

\section{Introduction}

Many shorebird species (Charadrii) nest in sites exposed to direct solar radiation (hereafter exposed sites) as a way to reduce predation risk on incubating adults (Grant 1982; Maclean 1984; Amat and Masero 2004a). This may represent a serious challenge for species nesting in hot environments, as they have to face stressful thermal conditions (Grant 1982; Brown and Downs 2003; Amat and Masero 2004b). Because of high radiant heat loads, ground-nesting shorebirds usually become heat-stressed as ambient temperatures ( $T_{a}$ ) rise (Grant 1982; Brown and Downs 2003; Amat and Masero 2004b). Thus, in the Kentish plover Charadrius alexandrinus, the body temperature $\left(T_{b}\right)$ increases with $T_{a}$ (Amat and Masero 2007).

Shorebirds incubating in exposed nests show remarkable plasticity in their behavioural and physiological strategies to alleviate heavy heat loads (Grant 1982; Downs and Ward 1997; Brown and Downs 2003; Amat and Masero 2004b). Incubating Kentish plovers resorted to bellysoaking (i.e., wetting of the ventral plumage; Maclean 1974) at $T_{a} \Gamma 36^{\circ} \mathrm{C}$ (Amat and Masero 2007). Above this $\mathrm{T}_{\mathrm{a}}$, the $\mathrm{T}_{\mathrm{b}}$ of plovers may increase up to $3^{\circ} \mathrm{C}$ above the average $T_{b}$ (Amat and Masero 2007), which for shorebirds is $41^{\circ} \mathrm{C}$ (McNab 1966; Prinzinger et al. 1991).

The increase in $T_{b}$ with increasing $T_{a}$ may be either regulated by the individual itself or forced if total heat storage exceeds the capacity for heat loss (IUPS Thermal Commission 2003). Kentish plovers deserted their nests in southern Spain when $\mathrm{T}_{\mathrm{a}} \mathbf{\Gamma} 45^{\circ} \mathrm{C}$ and they had no possibility of belly-soaking (Amat and Masero 2004b), which suggests that the increase in $T_{b}$ with increasing $T_{a}$ in this species is unregulated. In addition, when the plovers leave their nests to belly-soak, egg temperatures increase to levels that may compromise embryo survival (Amat and Masero 2007). 
Therefore, any mechanism that allows the plovers to maintain $\mathrm{T}_{\mathrm{b}}$ within tolerable limits would facilitate nest attentiveness, and consequently nesting success.

The operative temperature $\left(\mathrm{T}_{\mathrm{e}}\right)$ is the temperature experienced by an animal as a result of the sum of $T_{a}$ and any temperature increment or decrement that results from radiative and convective factors (Bakken 1976). At the temperatures at which Kentish plovers were observed to belly-soak in southern Spain $\left(36.8-43.6^{\circ} \mathrm{C}\right.$, Amat and Masero 2007), the operative temperatures experienced by plovers attending nests in standing postures would range from 45 to $54^{\circ} \mathrm{C}$ (Amat and Masero 2004b). Because in these situations $T_{e} \Gamma T_{b}$, the heat flux would be driven into the animals' bodies, and the plovers would be in thermal stress. Given that the increase in $T_{b}$ with $T_{a}$ in Kentish plovers seems unregulated, a possibility for plovers attending nests in exposed sites to reduce $T_{b}$ without losing body water through evaporative cooling would be via behavioural mechanisms such as bellysoaking, which may increase heat loss through convection. Although it has been suggested that belly-soaking is a behavioural solution to quickly reduce excess body heat (see Amat and Masero 2007), an empirical demonstration of this is lacking. Therefore, in this paper we tested whether belly-soaking would cause a reduction in $\mathrm{T}_{\mathrm{b}}$ in heat-stressed Kentish plovers nesting in a hot environment.

\section{Materials and methods}

Study site and field procedures

The study was conducted at Fuente de Piedra lake in southern Spain $\left(37^{\circ} 06^{\circ} \mathrm{N}, 4^{\circ} 45^{\circ} \mathrm{W}\right)$, described in Amat et al. (1999). At this lake, Kentish plovers mainly nest in exposed sites, and face stressful thermal conditions (Amat and Masero 2004a, b).

To record $\mathrm{T}_{\mathrm{b}}$ of plovers and simulate the effects of bellysoaking, we captured incubating birds $(n=31)$ at their nests using walk-in traps between 1200 and 1500 h (GMT) on sunny days. This period corresponds to the hottest part of the day (Amat and Masero 2004b). Upon capture, we noted the sex of the birds and whether they were panting (see description in Grant 1982), which would indicate that they were heat stressed. A 36-gauge copper-constantan thermocouple probe (Omega Engineering, Stamford, CT, USA) was inserted about $1 \mathrm{~cm}$ into the cloaca, and $\mathrm{T}_{\mathrm{b}}$ was measured to the nearest $0.1^{\circ} \mathrm{C}$ with an Omega $\mathrm{HH} 21$ microprocessor thermometer, which was calibrated to the nearest $0.1^{\circ} \mathrm{C}$ against a standard thermometer. Air temperature was measured $5 \mathrm{~cm}$ above ground level $\left(\mathrm{T}_{\mathrm{a} 5}\right)$ immediately after we took $\mathrm{T}_{\mathrm{b}}$.
To induce an increase in $\mathrm{T}_{\mathrm{b}}$, we then placed the plovers inside cloth (cotton) bags on the ground in exposed sites for $5 \mathrm{~min}$. After 5 min we again measured $\mathrm{T}_{\mathrm{b}}$ and temperature inside the bag. We used cloth bags because they allowed circulation of air inside them. We noted whether or not the birds were panting when they were removed from the bag. Immediately after this second measurement of body temperature, we wetted the ventral parts of plovers by submerging these parts in fresh water (2 cm deep, $20-25^{\circ} \mathrm{C}$ ) for about $10 \mathrm{~s}$. In less than $5 \mathrm{~s}$ after this, we measured $\mathrm{T}_{\mathrm{b}}$ for a third time. The time elapsing from the moment at which the bird was removed from the bag until ventral wetting was $90 \mathrm{~s}$.

An elevation in $\mathrm{T}_{\mathrm{b}}$ inside the bag may be a consequence not only of exposure to high temperature, but also to the stress of capture. Note, however, that with our experimental procedure we did not aim at simulating the thermal conditions experienced by the plovers at their nests, but only to test whether after elevating body temperature, the plovers may alleviate excessive body heat by bellysoaking.

\section{Statistical analyses}

We found no significant difference between $\mathrm{T}_{\mathrm{b}}$ of males $(41.4 \pm 0.63, \mathrm{n}=11)$ and females $(41.2 \pm 0.84, \mathrm{n}=20)$ (Student's t-test for independent data: $\mathrm{t}=0.87$, $\mathrm{df}=29$, $\mathrm{P}=0.389$ ), and therefore analysed the data of the two sexes together. A general linear mixed model (GLMM) was used to test the effect of treatment (three fixed levels: plover incubating, plover inside the bag, and plover wetted) on $\mathrm{T}_{\mathrm{b}}$. Plover identity was included as a random effect in the model, since GLMMs can be viewed as an extension of general linear models accounting for repeated measures of the same individual by including subject as a random factor in the model. For post-hoc analyses, we used pair-wise comparisons (Tukey HSD test). Statistical analyses were conducted using STATISTICA (StatSoft 2001). Mean values are presented with $\pm 1 \mathrm{SD}$.

\section{Ethical note}

For the experiment we only captured birds nesting in exposed sites, which are in better body condition than those nesting in covered sites (Amat and Masero 2004a). The maximum temperature inside the cloth bag during our experiment was slightly lower (range $36.2-49.3^{\circ} \mathrm{C}$, Fig. 1) than the maximum $\mathrm{T}_{\mathrm{a} 5}$ faced by incubating Kentish plovers at Fuente de Piedra $\left(51^{\circ} \mathrm{C}\right.$, J.A. Amat, unpublished data). Our experimental protocol had no negative effects on nesting success, as the plovers resumed incubation shortly after being released. To prevent the eggs from overheating while the nest was unattended because the adults had been 


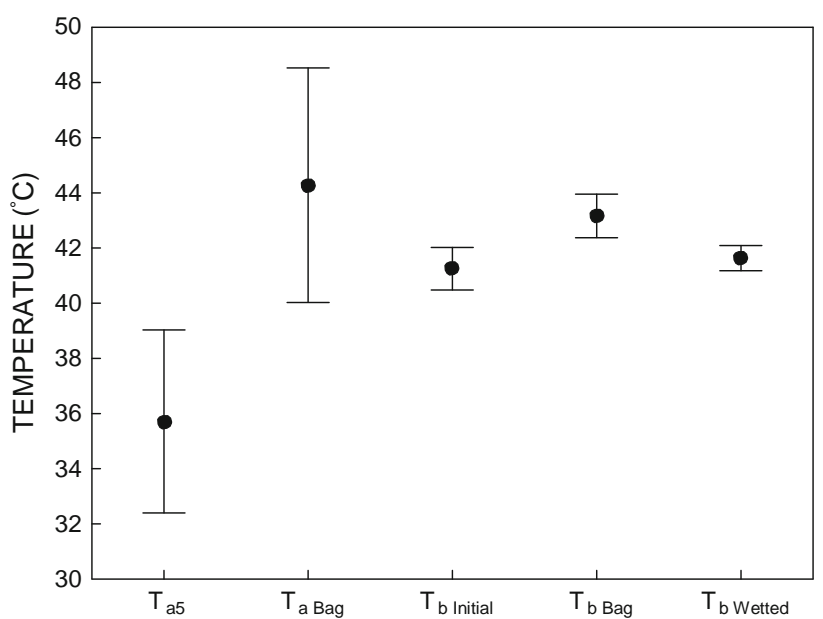

Fig. 1 Ambient temperature beside exposed nests $\left(T_{a 5}\right)$, temperature inside a cloth bag at ground level beside nests $\left(\mathrm{T}_{\mathrm{a}}\right.$ Bag$)$, and body (cloacal) temperatures of incubating Kentish plovers (mean $\pm 1 \mathrm{SD}$ ) $(\mathrm{n}=31)$. Temperatures of plovers were recorded immediately after being captured $\left(\mathrm{T}_{\mathrm{b} \text { Initial }}\right)$, then the plovers were placed inside a cloth bag for $5 \mathrm{~min}$ at ground level in exposed sites beside nests, after which body temperature was recorded again $\left(\mathrm{T}_{\mathrm{b}}\right.$ Bag $)$. Immediately after the plovers were removed from the bag, their ventral parts were wetted to simulate belly soaking, and body temperature recorded once more $\left(\mathrm{T}_{\mathrm{b} \text { Wetted }}\right)$

captured, we shaded the nest with twigs of Arthrocnemum glaucum until adults returned to the nests.

\section{Results}

When we captured the plovers $(n=31)$, their $T_{b}$ values were similar to the average $\mathrm{T}_{\mathrm{b}}$ for shorebirds (41.2 $\pm 0.77^{\circ} \mathrm{C}$, Fig. 1 ; see McNab 1966; Prinzinger et al. 1991), and only $6.5 \%$ of them were panting.

$\mathrm{T}_{\mathrm{b}}$ differed significantly across the experiment (GLMM; treatment: $\left.F_{2,60}=80.3, P \backslash 0.0001\right)$. After having been enclosed for $5 \mathrm{~min}$ in a cloth bag at ground level in exposed sites, inside which the temperature was on average $8.6^{\circ} \mathrm{C}$ higher than outside (Fig. 1), the Kentish plovers raised their body temperature on average $1.9^{\circ} \mathrm{C}$, a highly significant difference when compared to their body temperature before being introduced into the bag (post-hoc Tukey's test: $\mathrm{P} \backslash 0.001)$. The plovers were likely heat stressed inside the bag, as $87.1 \%$ of them $(n=31)$ were panting when removed from it.

When we simulated belly-soaking by wetting the ventral parts immediately after removing the birds from the bag, the Kentish plovers lowered their $\mathrm{T}_{\mathrm{b}}$ (Fig. 1) by $1.5^{\circ} \mathrm{C}$, which was a significant difference when compared with $T_{b}$ inside the bag (post-hoc Tukey's test: $\mathrm{P} \backslash 0.001$ ). $\mathrm{T}_{\mathrm{b}}$ after belly-soaking was only $0.4^{\circ} \mathrm{C}$ higher than $\mathrm{T}_{\mathrm{b}}$ before the birds were introduced into the bag (Fig. 1); this difference was not significant (post-hoc Tukey's test: $\mathrm{P}=0.05$ ).
These results indicate that belly-soaking contributed to quickly reducing $\mathrm{T}_{\mathrm{b}}$ in heat-stressed birds.

\section{Discussion}

An elevated $\mathrm{T}_{\mathrm{b}}$ can not be maintained for long periods because the body proteins may suffer serious alterations that can lead to the death of individuals (Schmidt-Nielsen 1990). We have shown that belly-soaking served to reduce $\mathrm{T}_{\mathrm{b}}$ of heat-stressed birds immediately after plumage wetting, suggesting that for Kentish plovers incubating in exposed nests in hot environments, belly-soaking is a thermoregulatory behavioural solution to quickly reduce excess body heat.

The body temperature of plovers was $0.4^{\circ} \mathrm{C}$ higher after experimental belly-soaking than before they were introduced inside the bag. We measured $\mathrm{T}_{\mathrm{b}}$ immediately after plumage wetting, so it is possible that $T_{b}$ continues to diminish over a longer period until it reaches values similar to those prior to belly-soaking, as happens with egg temperatures when moisture is applied to overheated eggs (Amat and Masero 2007).

The reduction in $T_{b}$ after plumage wetting may be achieved by convection or by evaporative cooling from water on the body's surface. The first mechanism would be very important just immediately after belly-soaking, and would be more effective with an increasing difference in temperatures between the water and the body of individuals. The cooler the water the quicker the transmission of temperature between the individual and water. Evaporative cooling after belly-soaking may also be very important, especially once the birds return to their nests. When shorebirds belly-soak, their feathers are saturated with water (Howell 1979; Schardien and Jackson 1979; Grant 1982). Because of this, the total resistance, that is the total heat transfer from the environment to body tissues (IUPS Thermal Commission 2003), is probably reduced by reducing coat resistance, and in hot and arid environments the saturation of plumage with water may also determine the amount of water available for evaporation (McCafferty et al. 1997a, b). The saturation of the ventral plumage with water may be important because this would allow the plovers to stay for longer periods at their nest. This may be adaptive during hot conditions because when the plovers leave their nests, the eggs overheat to levels that may be critical for embryos (Amat and Masero 2007).

Acknowledgments This study was financially supported by Dirección General de Investigación Científica y Técnica (research grant PB95-0110). Field work was authorized by Consejería de Medio Ambiente, Junta de Andalucía, which also provided accommodation. We thank A. Arroyo, R. Camarena, J. M. Ramírez, M. RendónMartos, J. Rubio and M. Vázquez for their help during field work, as 
well as two anonymous referees for their comments on a previous version. During manuscript preparation, we were funded by Dirección General de Investigación with EU-ERDF support (research grant CGL2005-01136/BOS).

\section{References}

Amat JA, Masero JA (2004a) Predation risk on incubating adults constrains the choice of thermally favourable nest sites in a plover. Anim Behav 67:293-300

Amat JA, Masero JA (2004b) How Kentish plovers, Charadrius alexandrinus, cope with heat stress during incubation. Behav Ecol Sociobiol 56:26-33

Amat JA, Masero JA (2007) The functions of belly-soaking in Kentish plovers Charadrius alexandrinus. Ibis 149:91-97

Amat JA, Fraga RM, Arroyo GM (1999) Brood desertion and polygamous breeding in the Kentish plover Charadrius alexandrinus. Ibis 141:596-607

Bakken GS (1976) A heat transfer analysis of animals-unifying concepts and application of metabolism chamber data to field ecology. J Theor Biol 60:337-384

Brown M, Downs CT (2003) The role of shading behaviour in the thermoregulation of breeding crowned plovers (Vanellus coronatus). J Therm Biol 28:51-58

Downs CT, Ward D (1997) Does shading behavior of incubating shorebirds in hot environments cool the eggs or the adult? Auk 114:717-724
Grant GS (1982) Avian incubation: egg temperature, nest humidity, and behavioral thermoregulation in a hot environment. Ornithol Monogr 30:1-75

Howell TR (1979) Breeding biology of the Egyptian plover, Pluvianus aegypticus (Aves: Glareolidae). Univ Calif Publ Zool 104:1-76

IUPS Thermal Commission (2003) Glossary of terms for thermal physiology. J Therm Biol 28:75-106

Maclean GL (1974) Belly-soaking in the Charadriiformes. J Bombay Nat Hist Soc 72:74-82

Maclean GL (1984) Arid-zone adaptations of waders (Aves: Charadrii). S Afr J Zool 19:78-81

McCafferty DJ, Moncrieff JB, Taylor IR (1997a) The effect of wind speed and wetting on thermal resistance of the barn owl (Tyto alba). I: Total heat loss, boundary layer and total resistance. J Therm Biol 22:253-264

McCafferty DJ, Moncrieff JB, Taylor IR (1997b) The effect of wind speed and wetting on thermal resistance of the barn owl (Tyto alba). II: Coat resistance. J Therm Biol 22:265-273

McNab BK (1966) An analysis of the body temperatures of birds. Condor 68:47-55

Prinzinger R, Preßmar A, Schleucher E (1991) Body temperature in birds. Comp Biochem Physiol 99A:499-506

Schardien BJ, Jackson JA (1979) Belly-soaking as a thermoregulatory mechanism in nesting killdeers. Auk 96:604-606

Schmidt-Nielsen K (1990) Animal physiology: adaptation and environment, 4th ed. Cambridge University Press, Cambridge

StatSoft (2001) STATISTICA (data analysis software system), version 6 . StatSoft, Tulsa 